\title{
Competency-Based Learning for Motivation and Academic Performance in a Pre-calculus Course
}

\author{
Manuel P. Rosales Almendra* \\ Departamento de Ingenierías, Centro Universitario de la Costa Sur, Universidad de Guadalajara, Guadalajara, México \\ *Corresponding author: manuel.ralmendra@academicos.udg.mx \\ Received October 03, 2018; Revised November 22, 2018; Accepted January 11, 2019
}

\begin{abstract}
This research evaluated the effect of the Competency-Based Learning strategy supported by the Web on academic performance and motivation variables, in a Pre-calculus distance course. Moodle was used as the management platform for the course. The participants in the study were students of recent entry to the university in the careers of Engineering in Teleinformatics and Engineering in Works and Services at the University Center of the South Coast of The University of Guadalajara. The Motivated Strategies for Learning Questionnaire (MSLQ) was applied at the beginning and at the end of the instruction to evaluate the significance of the Competency-Based Learning (CBL). Two groups were formed, the experimental group composed of students who participated under the Competency-Based Learning strategy, and the control group, who completed the pre-calculus course in a face-to-face fashion. The data provided in the present study was analyzed using the Statistical Analysis System (SAS), version 9.4. $t$-tests were performed for independent and paired samples. Parametric Analysis of Variance (ANOVA) was used to evaluate the significance of the academic performance variables and motivation of the students submitted to the CBL strategy. The Motivation variable was evaluated through a pre-test and a post-test. The results showed that the students who participated under the instructional strategy of CBL in the Pre-calculus course obtained higher academic performance than those obtained by their peers in the traditional group. The students who took the course under the CBL showed the same levels of intrinsic motivation throughout the course. The target levels of extrinsic orientation of the students who participated in the experimental group suffered changes in their levels. The results of the analysis supported the hypothesis and showed that the experimental group reached levels of intrinsic motivation superior to those achieved by the participants in the control group.
\end{abstract}

Keywords: competency-based learning, teaching of mathematics, intrinsic and extrinsic motivation, and academic performance

Cite This Article: Manuel P. Rosales Almendra, "Competency-Based Learning for Motivation and Academic Performance in a Pre-calculus Course." American Journal of Educational Research, vol. 7, no. 1 (2019): 58-63. doi: 10.12691/education-7-1-9.

\section{Introduction}

The research presented here was conducted at the University Center of the South Coast (CUCSUR) of the University of Guadalajara (UdeG), Mexico. The CUCSUR serves a population of 3500 students. Ninety percent of the population is urban and the remaining 10\% is rural. Currently, the CUCSUR Engineering Department serves 590 students distributed in the following careers: Engineering in Works and Services (IOS) 215, Teleinformatics Engineering (INTEL) 184, Mechatronics Engineering (IM) 184, and International Trade and Process Engineering (INPROCI) 191. This study focused specifically on the students of the careers of INTEL and IOS because of their low academic performance and high rates of reprobation.

Today, traditional teaching systems are geared towards training students for the same jobs they have been doing since long ago. This has put, at the center of attention, many higher education institutions who have undertaken important efforts to train students who demand new skills and competencies to meet the demands of university studies. The demands and needs that the students pose and that the institutions of higher education must confront are of two kinds [1]. The first has to do with the work of improving the knowledge and skills that students need to develop themselves in a free and autonomous way. The second one is related to the generation of learning scenarios that are relevant to the needs of society.

\section{Justification}

The deficiencies of the students' abilities to meet the demands of university studies put them in a situation of vulnerability. Some elements such as inadequate previous knowledge, motivation, inappropriate attitudes towards learning and the low capacity of psychological recovery, etc., are factors that affect drop out rates and the academic performance of higher-level students. 
It is not surprising that students feel more integrated to the extent that their abilities enable them to cope effectively with the intellectual demands of university life. Other factors that have been identified and that influence the continuity of student training are the deficiencies in their abilities to meet university challenges such as poor prior knowledge and inappropriate attitudes towards learning.

Despite the efforts of higher education institutions to improve the quality of their educational programs, drop out, academic backwardness, high failing rates, and low academic performance remain a constant problem in the careers of the areas of engineering [2]. The phenomenon of the reproach implies an increase in the rate of drop out in the engineering careers; this has had a negative psychological effect that has impacted students' ability to complete their programs efficiently [3].

The pedagogical strategies designed by the institutions must be student-focused so that the students can develop the necessary skills to access disciplinary knowledge as well as the development of competencies for the solution of mathematical problems and critical thinking skills. On the other hand, the implementation of information and communication technologies (ICT) in university spaces is known to promote learning scenarios that allow an effective interaction between instructors-students, students-students and students-contents that encourage and improve the development of skills and critical thinking skills in students. In this sense, instructors have shown a variety of benefits from the use of technology, including instructional delivery systems.

One of the most challenging problems that educational institutions currently face is that of teaching mathematics. Some studies attribute this problem to the current methodological schemes, which are incapable of enhancing the development of mathematical thinking skills that allow students a broad use of mathematical concepts for the solution of problems [4,5].

The evaluation techniques are limited to verifying the memorization of information and facts, dealing rarely with challenging the student to reach higher cognitive levels of comprehension. The teaching professional must be clear that the intention of teaching is for students to learn, to build their own knowledge, and to serve them not only for their student stage but also for everyday activities. The lack of mathematical skills in students entering higher education institutions is a factor that significantly affects terminal efficiency and of course academic performance.

According to reports issued [6], the discursive exposure used by teachers became uncomfortable, unmotivating and even frustrating, so evidenced by the students' assessments at the end of each semester. According to data provided by the School Control Coordination of the CUCSUR, from 2010 to 2013, the number of students who failed in the IOS's career increased by $50 \%$, and the average drop out rate reached $35 \%$.

For the case of the students of the INTEL's career the behavior was similar, the number of failed increased by $11 \%$, and the drop out rate defection reported an average increase of $23 \%$. The previous data reflected a problem that has been growing, forcing the institutions to undertake actions that contemplate remedial courses.
Mathematics is without a doubt a problematic topic in terms of skills acquisition and drop out rates; therefore, the remedial courses become fundamental, not only because they seek to standardize the levels of comprehension of the contents of a course, but also because they improve the students' academic performance, and decrease drop out levels.

This research explored the use of technology as a tool to support the teaching and effective learning of mathematics. It sought to provide a greater breadth for the teaching of mathematics, and thereby improve student learning. The fact that motivation is an important element in the formative process of the students learning was also assumed. Motivation was examined as an affective trait of students in subjects such as mathematics; promoting it implies a great challenge for instructors.

\section{Competency-Based Learning}

The competency-based learning (CBL) strategy proposed in this study has its theoretical basis in constructivism which is believed to be more effective than traditional instruction because it adapts to needs and reduces the differences between students' performance. Under the CBL approach students work only with the material they are willing to learn to achieve the understanding of mathematics; this suggests that the courses be divided in small units so that students can show competence in one unit before moving on to the next [7]. The CBL focuses on an individualized instruction based on the needs of students, to ensure that they reach the objectives of the readings.

The concept of competencies was proposed by Chomsky [8] within the framework of the theory of the Generative Transformational Grammar where he defined competence, from the perspective of language, as the mastery of the principles that govern language and acting as a manifestation of the rules underlying the use of language. To be able to develop competency-based instruction, it is necessary to have an idea of the concept; however, to try to define competencies is complicated work, since there are many different and varied definitions depending on context. The definition of competency varies according to the epistemological assumptions underlying the use of the term. In this work, competency will be assumed as the result of a process of integrating skills and knowledge.

According to Bloom [9], even though students vary in their learning styles and preferences, if the teacher is able to provide sufficient time and appropriate learning conditions, all students could achieve a high level of performance. Bloom noted that teachers in their traditional practice organize curricular content into smaller instructional units and then verify student progress at the end of each unit. These learning progress controls, according to Bloom, would be much more valuable if used as part of the learning process to provide students with information regarding individual learning difficulties and to prescribe specific remedial activities.

In designing and implementing a CBL program, four major tasks are to be implemented sequentially: a) definition of what is the learning object or domain of matter; (b) planning in order to achieve the domain; c) teaching to achieve mastery and (d) domain evaluation. 
CBL is an instructional strategy in which students can master a lesson before moving on to the next lesson. Bloom posited that a classroom with a competency-based learning approach, in contrast to the traditional form of instruction, would reduce the performance gaps among students of varying degrees of academic ability [10]. The CBL strategy divides the subject into units that have predetermined objectives. Students, alone or in groups, work each unit in an organized manner. The teacher evaluates and qualifies students after each unit to determine who has mastered the content and who needs more help. Students must show an $80 \%$ level of competency in the exams of each unit before moving on to new material [11].

Thus, students who manage to master the material have opportunities to move forward in the form of projects or through problem-solving tasks. On the other hand, students who fail to master the competency receive support through tutoring, peer mentoring, small group discussions or additional homework.

\section{Mathematics in Web-Based Environments}

The demand for competency-based learning environments has led institutions to exert pressure on teachers to teach through Web-based instructional environments. Mathematics today is the area of the curriculum that most contributes to the so-called school failure. Most students who do not get a college degree often cite their inability to develop the skills required in math. Due to this outcome, the IOS stream was evaluated in 2010 with the purpose of modifying the curriculum [12]. Some of the results generated from the evaluation process indicated the need to reinforce students' skills and competencies in solving high-level mathematical problems.

There is agreement that the technological development of information systems benefits almost all areas of human activity. Among the possible models of information technologies, using Web-based environments as complementary support to the courses of mathematics and statistics are increasingly common given the advantages that they provide. These advantages include greater interaction between students and instructors and a more efficient communication with the students [13].

In their study on teaching mathematics with technology, Moyer-Packenham, and Suh [13] examined the influence of virtual manipulation on different group performances during teaching in an experiment with high school students. The experiment focused on the concept of two rational numbers (equivalent fractions and additional fractions with unequal denominators). The authors considered three types of groups, one with a low performance, two with average performance and one with high performance. Three groups used virtual manipulation of technology and one group used physical manipulation of technology. The results reported by the researchers showed significant differences between the groups of students who used virtual manipulation. No differences were found between the students of the average performance group in the virtual manipulation and physical manipulation treatments. However, the foregoing implies that the incorporation and use of technology in the teaching of mathematics can encourage students into taking an active role within the classrooms; for example, graphic technologies such as calculators, and Computerbased tools such as specialized software and simulators in Web-based instruction and practice are elements that have shown a significant improvement in science learning.

In the teaching of science, specifically in mathematics, technology support has resulted in a factor that makes it easier for students to understand concepts.

\section{Motivation in Web-Based Environment}

In Pintrich and Schunk's article [14] about motivation in education, the researchers determine that motivation is a basic construct to explain the academic performance of the students. They defined motivation as "The process by which targeted activity is instigated and sustained". Students with high levels of motivation are involved in tasks that are more difficult, make greater efforts and are more persistent in the face of obstacles, which generates greater skill and a considerable improvement in their academic performance [15].

The different concepts of motivation establish a frame of reference to think, feel and act about a specific course. Thus, for example, the motivating beliefs regarding mathematics determine the strategies students will use to complete their activities.

Vallerand et al. [16] in their article on motivation, defined two types of motivation, intrinsic and extrinsic. Intrinsic motivation is defined as behavioral factors that the person performs for pleasure, finds stimulating and allows them to perform when they exceed their own expectations. Extrinsic motivation refers to the behaviors adopted to achieve a goal or reward beyond the activity itself.

Bekele continues this idea of intrinsic and extrinsic motivation in technology-enhanced learning environments [17]. Bekele found that determinants of motivation and satisfaction in a Web-based learning environment include the attributes of technology, the quality of courses, participation, curriculum and support services. These determinants were found to boost cognitive effort, persistence, competencies and academic performance.

Other factors such as relevance, technological competencies and age, according to Moyer-Packenham and Suh [13], proved to be the best predictor of a positive change in motivation. As in the presence of the environments, the motivating factor plays important role in the planning process of a virtual learning environment; the motivation becomes a fundamental factor for success as it represents a potential benefit in the changes of the teaching of the mathematics online [18]. Therefore, it is imperative that the instructional strategy be designed considering the need to transfer the motivational factors to the students.

\section{Metodology}

The premise of this study was to evaluate the effectiveness of the CBL methodology in a distance remedial Precalculus course in relation to math skills, academic performance and motivation of students. Under this premise, the levels of instruction that defined the treatments were established. 
The experimental treatment was designed using the CBL methodology and delivered at a distance while the control treatment was delivered in person.

Population and sample: the target population included all recent students of INTEL and IOS programs. These students completed a diagnostic test which purpose was to identify deficiencies in skills to solve math problems. Two groups were formed: the experimental one integrated by those students diagnosed with problems of mathematical skills and that will later face courses of Pre-calculus and who completed the distance course under the strategy of the CBL. The control group was formed with students who required remediation, and who decided to take the course face-to-face. The sample was non-probabilistic and both groups contained 30 students

Instruments: The first step of the research study was the application of a diagnostic test which objective was to gather information on the mathematical competencies of the students to solve problems modeling a standardized answer. It was a standardized test that allowed us to know the level of students' mathematical knowledge before starting the courses; the test included algebra problems, analytical geometry, and differential and integral calculus. It also used the instrument called MSLQ for its acronym in English Motivated Strategies for Learning Questionnaire [19]. The MSLQ questionnaire is composed of 81 items distributed in two sections, a motivational section and another one on learning strategies. The responses for the items use a seven points Likert scale, ranging from 1 (doesn't describe me at all) to 7 (completely describes me). The motivation section consists of 31 items with six scales related to different motivational aspects including: (a) Intrinsic goal orientation, (b) Extrinsic goal orientation, (c) Assessment of the task, (d) Self-efficacy beliefs, (e) Learning control beliefs, and (f) Anxiety.

The learning strategies section consists of 50 items: 31 items consider the use of different cognitive and metacognitive strategies and 19 items reacted with the management of students from different learning resources. The 50 items are grouped into nine scales that evaluate different aspects: (1) use of review strategies, (2) elaboration, (3) organization, (4) critical thinking, (5) metacognitive self-regulation, (6) time management and study environment, (7) effort regulation, (8) peer learning and (9) search for help.

In this investigation, only the motivational section was used. Students' academic performance was based on standardized tests designed by the Mathematics Academy of the CUCSUR Engineering Department.

Data analysis: Given the nature of the dependent variables, data were analyzed using analysis techniques of variance to compare the groups through the variable academic performance and the different scales of the motivation construct of the MSLQ Questionnaire in the learning environment. The raw data were transformed into ranks, as they did not conform to theoretical assumptions, such as independence and normality between groups and variance homogeneity.

The data collected on an ordinal scale do not meet the theoretical requirements that support a parametric statistical test. Therefore, it was necessary to transform the data. The transformation to ranges allows the application of parametric statistical techniques and avoids the use of non-parametric techniques.
The analyses were based on the averages of the ranges of the original data, except for the academic performance, which analysis was made on the original data since they fulfilled the theoretical assumptions of the statistical test in question.

Statistical $t$ tests were applied for paired samples to evaluate the probable changes in the levels of intrinsic motivation scales and extrinsic motivation within the experimental group. To have an overview of the motivational profile of the students of the experimental group, the motivation was assessed with all their scales except for the scale of anxiety; this analysis was interesting to evaluate the change in the motivational levels of the students at the end of the instruction.

For this test the averages of the pre-test and post-test ranges were considered. For the case of academic performance and the different scales of the motivation variable, Student's $t$-tests were used for independent samples. The tests were done to compare the effectiveness of the CBL strategy in the distance environment versus the face-to-face.

\section{Results}

The analyses considered only intrinsic motivation and extrinsic motivation to evaluate the changes in the motivational profiles of the students within the experimental group.

The anxiety scale was discarded to have a closer indicator of the presence of student motivation. The research-specific questions were the following:

What is the difference in the motivation intrinsic of students before (pre-test) and after (post-test) implementing the instructional strategy of $\mathrm{CBL}$ in the Pre-calculus course?

Hypothesis Ho1: There were no statistically significant differences in the level of intrinsic motivation of the students before (pre-test) and after (post-test) the implementation of the CBL instructional strategy in the Pre-calculus course.

The difference observed between the averages of the groups was a $t$-value of -2.42 . The size of the effect was $d=.072$, according to the established guide [20]; this is considered a very small effect size. The criterion established by Cohen considers a large effect for higher values of . 80; Values between $.2<d<.8$ are considered a mid-size effect. The results showed enough evidence not to reject the hypothesis Ho1: $t(24)=-.36, p<.722$.

What is the difference in the intrinsic motivation of the students before (pre-test) and after (post-test) implementing the instructional strategy of CBL in the course of Pre-calculus?

Hypothesis Ho2: There were no statistically significant differences in the level of extrinsic motivation of the students before (pre-test) and after (post-test) implementation of the CBL instructional strategy in the course of Pre-calculus.

The results reported mean extrinsic orientation of the students prior to the application of the instruction ( $\bar{X}=111.09, S=36.09$ ) and after the application of the instruction ( $\bar{X}=89.091, S=41.95$ ).

The results showed enough evidence that led to the rejection of the hypothesis Ho2: $t(24)=2.42, \mathrm{p}<.0234$. The size of the effect was $d=.278$.

What is the difference in the extrinsic motivation of the students before (pre-test) and after (post-test) of 
implemented the instructional strategy of CBL during the Pre-calculus course?

Hypothesis Ho3: There are no statistically significant differences in the level of integral motivation of the students before (pre-test) and after (post-test) implementing the instructional strategy of the CBL during the Pre-calculus course.

The average of the levels of motivation before the application of the instruction $(\bar{X}=388, S=100.08)$ and after application of the instruction $(\bar{X}=396, S=121.99)$ the difference observed between the averages was 8.0, and the confidence interval to $95 \%$ for this difference was extended from -29.57 to 53.57 . The size of the effect was $d=.076$. According to the results of the analyses, the mean levels of motivation before and after the instruction remained unchanged, $t(24)=0.60, p<.71$. The results showed enough evidence not to reject the Ho4: hypothesis.

What is the difference in the academic performance of the group of students who participated in the remedial Pre-calculus course in the distance modality under the instructional strategy of the CBL with respect to the students who participated in the face-to face course?

Hypothesis Ho4: There are no statistically significant differences in the average academic performance of the students who completed the Pre-calculus remedial course under the CBL strategy and the group that completed the remedial course in the face-to-face strategy.

The statistical procedure used also provides confidence intervals for the estimator of the difference between the academic performance averages of the group of students who participated under the CBL strategy and the group of students who did so under the Traditional approach. In this hypothesis, the original data were used, given that they fulfilled the theoretical assumptions required for the statistical test. The average of the group that participated under the strategy of the CBL ( $\bar{X}=84.52, S=21.39$ ) and the average of the group that participated in a traditional way ( $\bar{X}=69.35, S=15.56$ ). The assumption of equality of variances between groups was fulfilled, $F(26,16)=$ $1.89, p<.187$. The difference observed between the averages was $-15,166$, and its corresponding confidence interval to $95 \%$ was extended from -27.27 to -3.06 . The size of the effect was $d=.78$. The results led to Ho: rejection.

\section{Conclusions}

The results of this research argue that students participating in the CBL instructional strategy maintained their intrinsic motivation levels during the course, which meant a positive attitude towards the activities proposed in the course. The activities were designed in a familiar context to the students using both real and hypothetical problems. The results make it possible to infer that the students fulfilled their responsibilities and made a greater mental effort during the resolution of problems. These results differ from other researches [21] that used the MSLQ where they compared the effectiveness of the CBL's instructional strategy in the intrinsically oriented meta variable, before and after to completion of the instruction, and where authors conclude that the instructional strategy improved the intrinsic motivation of the students at the end of the course.

The target extrinsic orientation levels of the students who participated in the experimental group underwent changes in their levels. This can be attributed to the CBL instructional strategy influencing the extrinsic orientation goals, and thus their behaviors changed during the course. It is worth noting that many of the students who participated in the course showed their skills in technology management, and this encouraged them to take the course most likely under the belief that they could demonstrate their skills and abilities, not only in the learning of mathematics, but in the management and use of technology. The fact that students have modified (decreased) their extrinsic motivational orientation at the end of the course suggests that these students also modified (increased) their intrinsic motivational orientation.

The results of this study suggest the existence of statistically significant differences in the level of integral motivation of the students using the instructional strategy of the CBL as determined by pretest and post-test research. The test of this hypothesis was based on the component of value and expectations. The results of the analyses showed the existence of significant differences between pretest and posttest for motivation. Motivation levels were modified by CBL's instructional strategy at the end of the course. The results of the study showed that CBL's instructional environment offered students new and effective ways to address math learning, ways that would be more complicated under instructional approaches without technology support.

In the case of the variable academic performance, the students who participated in the experimental group achieved higher scores than those obtained by their peers from the traditional group. The results can be attributed to the expectations and interest that the course aroused in the students with the new methods. The results presented here coincide with other evidence of research reported on the influence of motivation on academic performance [17,22]. It is undeniable that the incorporation of technology promoted in the participants the opportunity and the desire to experience new ways of learning and to improve their academic performance. This finding is supported by other research [17] that reported factors that triggered motivation in Web-based learning environments.

In summary it can be concluded from this study that students achieved better when taught Pre-calculus using CBL than when taught using face-to-face methods.

\section{References}

[1] ANUIES. (2006). Consolidación y avance de la educación superior en México. Recuperado el 2 de febrero de 2011, de http://www.anuies.mx/secciones/convocatorias/pdf/consolidacion.pdf.

[2] Calvo, B. M. M.: Enseñanza eficaz de la resolución de problemas en matemáticas. Educación. Red de Revistas Científica de América Latina y el Caribe, España y Portugal, 32(1), 123-138 (2008).

[3] Departamento de Ingenierías. Informe de labores. Autlán, Jalisco, México (2010).

[4] Rosa, M., \& Lerman, S.: Researching online mathematics education: opening a space for virtual learner identities. Educational Studies in Mathematics, 78(1), 69-90. (2011).

[5] Turner, J. C., Bogner, W. K., \& Christensen, A.: Motivating mathematics learning: Changes in teachers' practices and beliefs 
during a nine-month collaboration. American Educational Research Journal, 48(3), 718-762 (2011).

[6] Academia de Matemáticas.: Informe de actividades. Centro Universitario de la Costa Sur Universidad de Guadalajara. Autlán, Jal. Mex. (2012).

[7] Bloom, B. S.: Mastery learning. En J. H. Block (Ed.), Mastery learning: Theory and practice (47-63). New York: Holt, Rinehart and Winston (1971).

[8] Chomsky, N.: El leguaje y el conocimiento inconsciente. En Colección y estudios literarios (Ed.), Reglas y representaciones. México: Fondo de Cultura Económica (1983).

[9] Bloom, B. S. (1984). The search for methods of group instruction as effective as one-to-one tutoring Educational Leadership, 41(8), 4-17.

[10] Guskey, T. R. Closing achievement gaps: Revisiting Benjamin s. Bloom's "learning for mastery." Journal of Advanced Academics 19(1), 8-31. (2007).

[11] Anderson, J. R. (Ed.). Learning and memory: An integrated approach (2 ed.). New York: John Wiley and Sons, Inc. (2000).

[12] Departamento de Ingenierías.: Plan de desarrollo del departamento de ingeniería. Autlán, Jalisco, México: Centro Universitario de la Costa Sur -UdeG (2016).

[13] Moyer-Packenham, P. S., \& Suh, J. M.: Learning mathematics with technology: The influence of virtual manipulatives on different achievement groups. Journal of Computers in Mathematics and Science Teaching, 31(1), 39-59. (2012).

[14] Pintrich, P. R., y Schunk, D. H. Motivation in education: Theory, research, and applications. Upper Saddle River, NJ: MerrillPrentice Hall. (2002).
[15] Kadioglu, C., y Kondakci, E. U. Relationship between learning strategies and goal orientations: A multilevel analysis. Eurasian Journal of Educational Research, 56, 1-22. (2014).

[16] Vallerand, R. J., et al.: On the assessment of intrinsic, extrinsic, and amotivation in education: Evidence on the concurrent and construct validity of the academic motivation scale. Educational and Psychological Measurement, 53, 159-172 (1993).

[17] Bekele, T. A.: Motivation and satisfaction in Internet-supported learning environments: A review. International Forum of Educational Technology \& Society, 13(2), 116-127. (2010).

[18] Iji, C. O., Abah, J. A., y Anyor, J. W. Educational cloud services and the mathematics confidence, affective engagement, and behavioral engagement of mathematics education students in public university in benue state, Nigeria. International Journal of Teaching and Learning in Higher Education, 30(1), 47-60. (2018).

[19] Pintrich, P. R., Smith, D. A. F., García, T., \& McKeachie, W. J.: A manual for the use of the motivated strategies for learning questionnaire (MSLQ). Ann Arbor, MI: University of Michigan (1991).

[20] Cohen, J. Weithted kappa: Nominal scale agreement with provision for scaled disagrement or partial credit. Psychological Bulletin, 70(4), 213-220 (1968).

[21] Partin, M. L., et al.: Yes I can: The contributions of motivations and attitudes on course performance among biology nonmajors. Journal of College Science Teaching, 40(6), 86-95 (2011).

[22] Turner, M., VanderHeide, K., y Fynewever, H.: Motivations for and barriers to the implementation of diagnostic assessment practices -a case study. Chemistry Education Research and Practice, 12(2), 142-157 (2010).

C) The Author(s) 2019. This article is an open access article distributed under the terms and conditions of the Creative Commons Attribution (CC BY) license (http://creativecommons.org/licenses/by/4.0/). 